\title{
GESTÃO DE RESÍDUOS SÓLIDOS NO MEIO RURAL: UM LEVANTAMENTO EM MUNICÍPIOS DO OESTE CATARINENSE
}

\author{
Daiane Bernardi ${ }^{1}$ \\ Debora Munaretto ${ }^{2}$ \\ Noélle Khristinne Cordeiro ${ }^{3}$ \\ Cidmar Ortiz dos Santos ${ }^{4}$
}

Resumo: O objetivo deste trabalho foi compreender as percepções da população rural sobre questões ambientais acerca dos resíduos sólidos na região oeste catarinense e identificar as diferentes formas de destino dado aos resíduos sólidos gerados pelas famílias. Aplicou-se um questionário com 16 questões fechadas a alunos do $1^{\circ}, 2^{\circ}, 3^{\circ}$ ano do ensino médio e pós médio pertencentes à instituição de ensino rural. Os resultados demonstraram que a coleta seletiva é entendida como questão importante, no entanto, métodos errôneos de descarte do lixo são utilizados, pois a conscientização da população não se encontra plenamente formada, sendo necessária atenção à educação ambiental, para que eventuais políticas públicas aplicadas obtenham sucesso.

Palavras-chave: Lixo; Descarte; Propriedades Rurais.

\footnotetext{
1 Universidade Tecnológica Federal do Paraná. E-mail: daiane ber@hotmail.com

2 Universidade de Passo Fundo. E-mail: deboramunaretto@outlook.com

${ }^{3}$ Universidade Estadual do Oeste do Paraná. E-mail: noellecordeiro@outlook.com

${ }^{4}$ Universidade Tecnológica Federal do Paraná. E-mail: cidmar@utfpr.edu.br.
}

Revbea, São Paulo, V. 14, № 2: 119-132, 2019.

revista brasileira educação ambiental 


\section{Introdução}

A geração de resíduos está associada à história da civilização humana, sendo o homem, o único ser vivo que não possui seus resíduos inteiramente reciclados e decompostos pela natureza (DURAZZINI; PARADELO, 2010, p. 58), pois devido à industrialização dos recursos naturais, os resíduos, que antes eram, em sua grande maioria, orgânicos e de rápida degradabilidade, hoje tornaram-se inorgânicos, levando décadas para degradação total.

Os resíduos gerados pelas atividades humanas têm se tornado um grande problema ambiental, responsáveis pela maior parte da agressão ao planeta (PONTES, 2017, p. 2), aliado ao crescimento, longevidade da população e o aumento do consumo de novas tecnologias, gerando a produção de imensas quantidades de resíduos (MAZZA et al., 2014, p. 685).

De acordo com o Instituto Brasileiro de Geografia Estatística (IBGE, 2012) há 5.570 municípios no território brasileiro, sendo $84,1 \%$ representado pela população urbana e $16,9 \%$ pela população rural, somando aproximadamente 35 milhões de brasileiros residentes em áreas rurais.

A população residente em áreas rurais representa número considerável de famílias, sendo diversas as atividades geradoras de resíduos sólidos realizadas por elas. A produção de resíduos sólidos no meio rural tem se tornado tão preocupante quanto no urbano, uma vez que a coleta de lixo rural no Brasil é realizada em apenas $31,6 \%$ dos domicílios, sendo o restante, cerca de $70 \%$ dos domicílios rurais, queimam, enterram ou lançam os resíduos em terrenos baldios, rios, lagos, igarapés ou açudes (PNRS, 2011, p. 46).

Em grande parte das regiões brasileiras o serviço de coleta de resíduos domésticos rurais é deficiente (PNRS, 2011, p. 46), sendo que no estado de Santa Catarina, o qual possui 295 municípios, apenas 190 deles, ou seja 64,4\%, possuem Plano de Gestão Integrada de Resíduos Sólidos (MMA, 2015).

$\mathrm{Na}$ região oeste do estado de Santa Catarina, apenas $14,2 \%$ das residências possuem acesso ao serviço de coleta, enquanto $85,8 \%$ das famílias são responsáveis pela destinação do seu próprio resíduo, sendo a maioria destas residências localizados em áreas rurais, onde usualmente emprega-se métodos incorretos de descarte (FRIESTINO; SILVA; NASCIMENTO, 2015, p. 112), sendo que esta gestão inadequada dos resíduos sólidos pode ser responsável por gerar problemas à saúde das pessoas que residem nesses ambientes, assim como ocasionar sérios problemas ao ambiente, como a contaminação da água, do solo e até dos alimentos produzidos nessas propriedades (CERETTA; SILVA; ROCHA, 2013, p. 18).

A situação de destinação dos resíduos conduzida pelos próprios geradores apresenta-se como um fato comum na zona rural de muitos municípios do país. Esta destinação errônea aliada à crença que a pouca quantidade de resíduos gerados na área rural não é suficientes para afetar o meio ambiente e a carência de coleta seletiva gera um grave problema, o qual merece de importante atenção (FREIRE et al., 2016, p. 53).

Revbea, São Paulo, V. 14, № 2: 119-132, 2019. 
Diante desta problemática, o objetivo deste estudo foi compreender as percepções da população rural sobre as questões ambientais que envolvem os resíduos sólidos na região oeste catarinense, e identificar as diferentes formas de destino dado aos resíduos sólidos domésticos gerados pelas famílias.

\section{Material e Métodos}

A pesquisa foi realizada com alunos regularmente matriculados em uma instituição de ensino rural, localizada no município de coordenadas latitude: $26^{\circ}$ 23' 39" S e longitude: 53 $04^{\prime}$ 41" W, na região oeste do estado de Santa Catarina.

Os alunos matriculados na instituição advêm do próprio município e municípios próximos, abrangendo o total de oito municípios.

Elaborou-se um questionário semiestruturado com 16 questões fechadas de múltipla escolha, onde ofereceu-se aos respondentes a possibilidade de opção entre uma das alternativas apresentadas em uma lista, onde o número de opções disponíveis por pergunta variou conforme a complexidade e necessidade (Apêndice 1).

A pesquisa foi realizada com alunos do $1^{\circ}, 2^{\circ} \mathrm{e} 3^{\circ}$ anos do ensino médio e alunos do pós médio, pertencentes à instituição de ensino, sendo os alunos orientados a responder o questionário junto aos seus familiares.

De acordo com informações cedidas pela instituição de ensino, no ano de 2017 a instituição contou com 124 alunos matriculados, o que corresponde à 124 famílias com seus filhos frequentando a instituição, estando estas envolvidas no ambiente escolar.

A aplicação do questionário foi realizada no mês de dezembro de 2017 , por meio eletrônico (e-mail, redes sociais), mantendo a identidade dos alunos oculta, sendo aplicado ao todo 35 questionários, o que representa cerca de $28,2 \%$ do total de alunos, que juntamente com seus familiares totalizam cerca de 136 pessoas.

Os sujeitos da pesquisa foram selecionados de forma aleatória, dispersos nas turmas de ensino médio e pós médio, e após a reunião dos questionários, estes foram agrupados conforme a similaridade de perguntas e respostas.

\section{Resultados e Discussão}

De acordo com as respostas obtidas, quando os entrevistados foram questionados sobre ter ou não conhecimento a respeito da coleta seletiva de lixo, todos os respondentes declararam saber do que se trata, e quando interrogados sobre sua percepção da importância de ser realizada a coleta seletiva dos resíduos, as respostas ficaram concentradas nas alternativas que

consideram a coleta como importante, muito importante e extremamente 
importante, tendo $60 \%$ dos entrevistados considerado a realização de coleta uma questão extremamente importante (Figura 1).

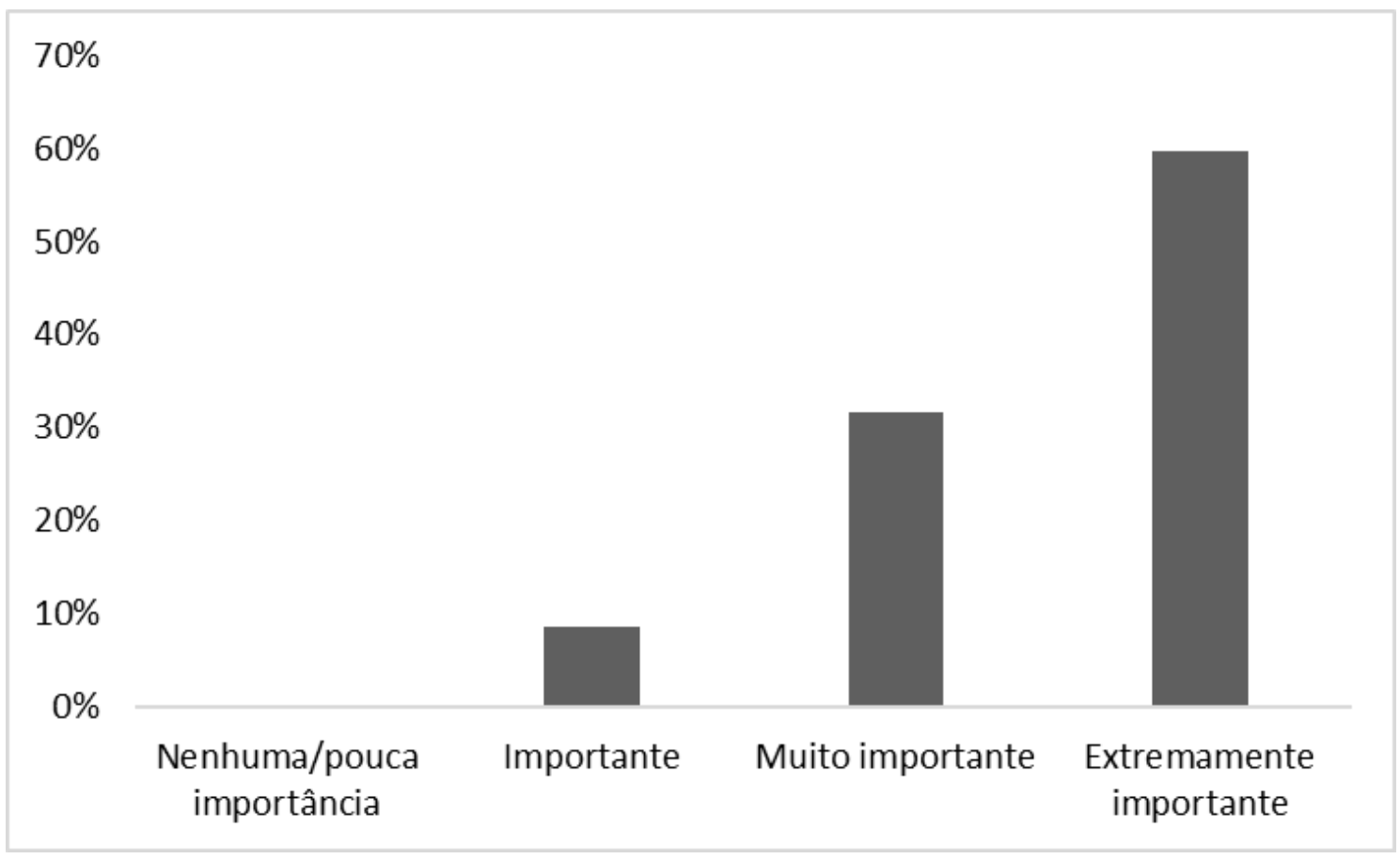

Figura 1: Percepção sobre a importância da coleta seletiva na região oeste de Santa Catarina.

Fonte: Os autores, 2018.

Pedroso (2010, p. 28) em pesquisa realizada com agricultores de uma fazenda do município de Itaqui - RS a respeito do conhecimento sobre coleta seletiva e sua importância, observou que $75,7 \%$ dos agricultores possui conhecimento sobre coleta seletiva e sua importância, o que significa que existe nestas propriedades pré-disposição dos moradores ao trabalho com coleta seletiva de lixo, o mesmo ocorre na presente pesquisa.

Segundo Persich (2011, p. 417), a conscientização e colaboração da população alvo apresenta uma corrente de extrema importância entre a sociedade e o poder executivo, pois possibilita melhor atuação das políticas públicas no município e maior facilidade na mobilização da comunidade.

Deve-se considerar que a informação e conscientização a respeito da temática dos resíduos sólidos deve ser trabalhada de forma contínua, a fim de tornar algumas atitudes ambientalmente corretas como rotineiras, já que os problemas relacionados ao lixo são persistentes.

Relacionado à esta importância dada a coleta seletiva, questionou-se sobre o entendimento dos alunos e seus familiares na relação entre os resíduos gerados, o meio ambiente e a qualidade de vida das famílias, onde $87,5 \%$ das respostas consideraram que estes três fatores têm muita relação entre si, reforçando a ideia de que a população residente no meio rural entende que a questão do resíduo produzido por elas tem impacto em suas vidas. 
Abordou-se ainda o tema da separação e deposição dos resíduos produzidos na propriedade. Quando questionado às famílias sobre a realização ou não da separação do resíduo orgânico do reciclável, a maioria $(68,6 \%)$ respondeu que a separação destes é realizada (Figura 2).

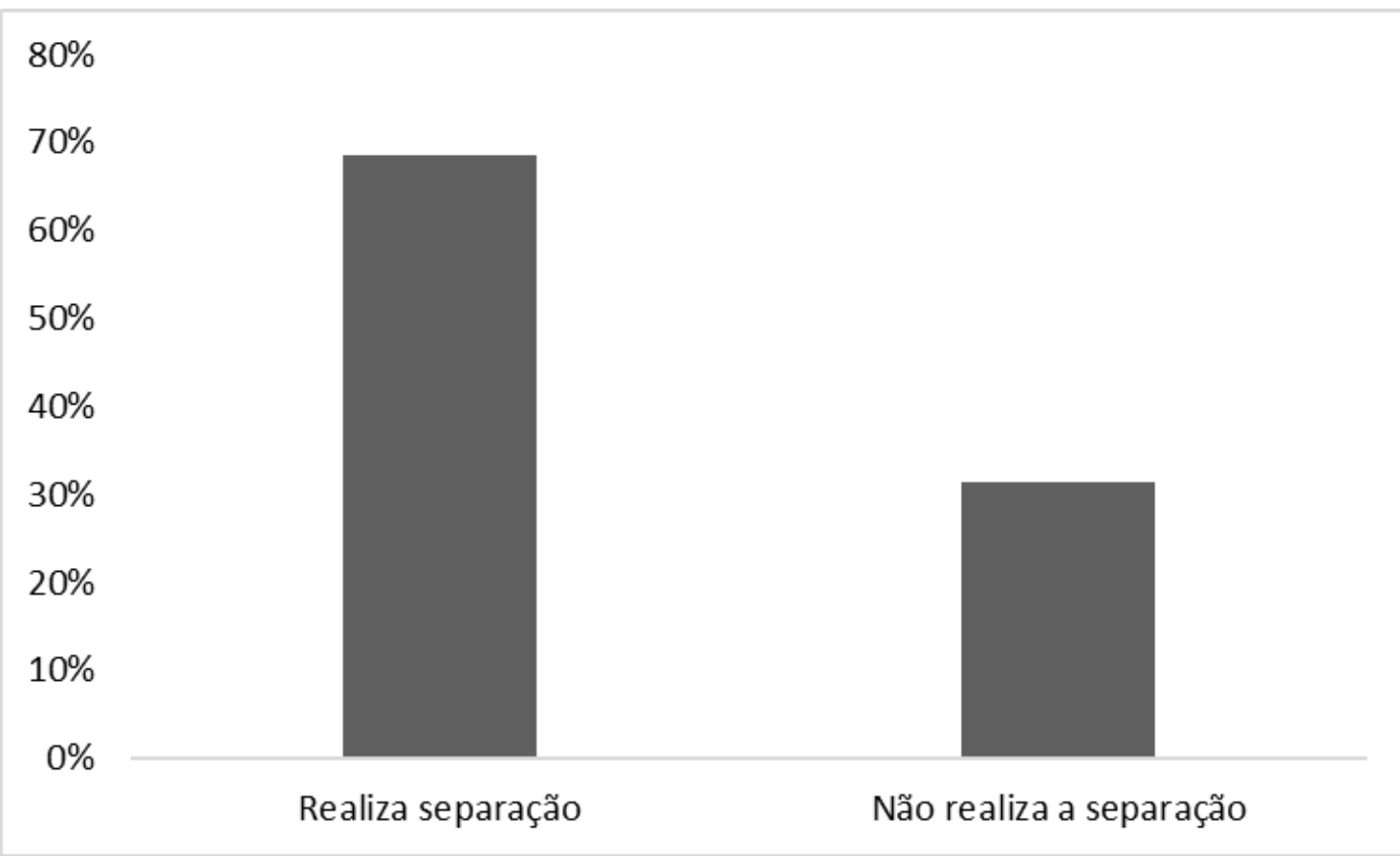

Figura 2: Realização de separação dos resíduos orgânicos do reciclável na região oeste de Santa Catarina. Fonte: Os autores, 2018.

A melhor maneira para o correto descarte dos resíduos, de modo geral, ainda é por meio da separação do mesmo em categorias como vidro, papel, metais e orgânico para posterior realização da coleta seletiva, no entanto, culturalmente na região oeste de Santa Catarina, observa-se que a separação dos resíduos, quando realizada, restringe-se à separação em reciclável/seco e orgânico, devido a quase ou total inexistência de coleta seletiva periódica no meio rural.

A Figura 3 demonstra a deposição dos resíduos orgânicos das residências quando estas realiza a separação do resíduo orgânico do reciclável pelos seus moradores. 


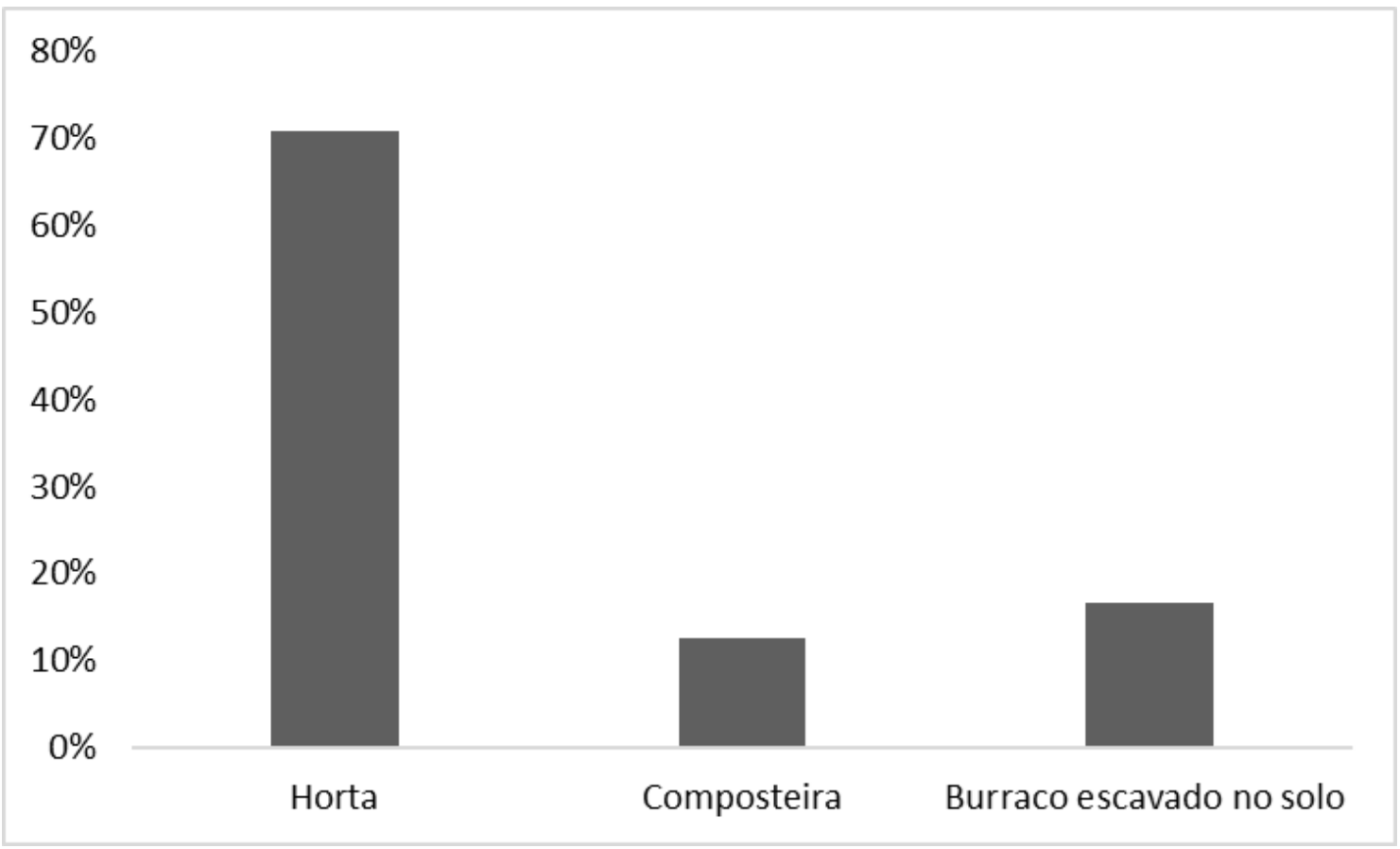

Figura 3: Destinação dada aos resíduos orgânicos das residências na região oeste de Santa Catarina. Fonte: Os autores, 2018.

Observa-se que grande parcela dos entrevistados $(70,8 \%)$ realiza a deposição dos resíduos orgânicos em hortas próprias como forma de realizar a adubação de canteiros para o cultivo de hortaliças. Esta forma de descarte utilizada apresenta-se uma forma rápida e eficiente, já que faz com que esses resíduos não se tornem um problema para a área rural.

No entanto, uma parte dos resíduos orgânicos, acaba sendo incorporada aos resíduos recicláveis, o que contribui para o mau cheiro oriundo da decomposição, problema este que poderia ser resolvido com programas educativos que fomentam a compostagem, como sugere (FREIRE et al, 2016, p. 55).

Segundo Wangen e Freitas (2010, p. 86), a compostagem doméstica de resíduos sólidos orgânicos domiciliares, se corretamente conduzida, não resulta na geração de mau cheiro ou atração de insetos vetores, no entanto, esta prática acaba requerendo maior atenção para sua manutenção, devido a necessidade de local especifico e necessidade de espera para a utilização do húmus, tornando o descarte em hortas um meio mais rápido e barato.

Esta porcentagem contrapõe-se ao que Pedroso (2010, p. 31) relata, pois segundo o autor, $75,7 \%$ dos agricultores pesquisados nunca separam 0 lixo produzido, e 24,3\% realiza a separação ocasionalmente.

Esta diferenciação pode estar relacionada ao hábito de vida das pessoas e à preferência e possibilidade pelo cultivo de hortas, onde há o descarte do resíduo orgânico nos canteiros ou composteiras, como também pode estar 
relacionada ao tipo de residência das famílias, pois no estudo de Pedroso (2010, p. 25), realizado em uma fazenda no município de Itaqui-RS, uma parcela dos pesquisados residia em alojamento, o que limitava a destinação do lixo em certos locais.

Aos entrevistados que disseram realizar a separação do lixo seco ou reciclável (plástico, vidro, papel e outros), questionou-se a respeito do local e forma de descarte. Como observado na Figura 4, a maioria dos entrevistados $(65,7 \%)$ alegou descartar o lixo produzido na propriedade através da coleta seletiva, um resultado que se difere do esperado, já que quando perguntados sobre a existência de coleta seletiva no local de moradia, $57,1 \%$ dos entrevistados disseram não possuir em seu município algum serviço público de coleta domiciliar de lixo na zona rural.

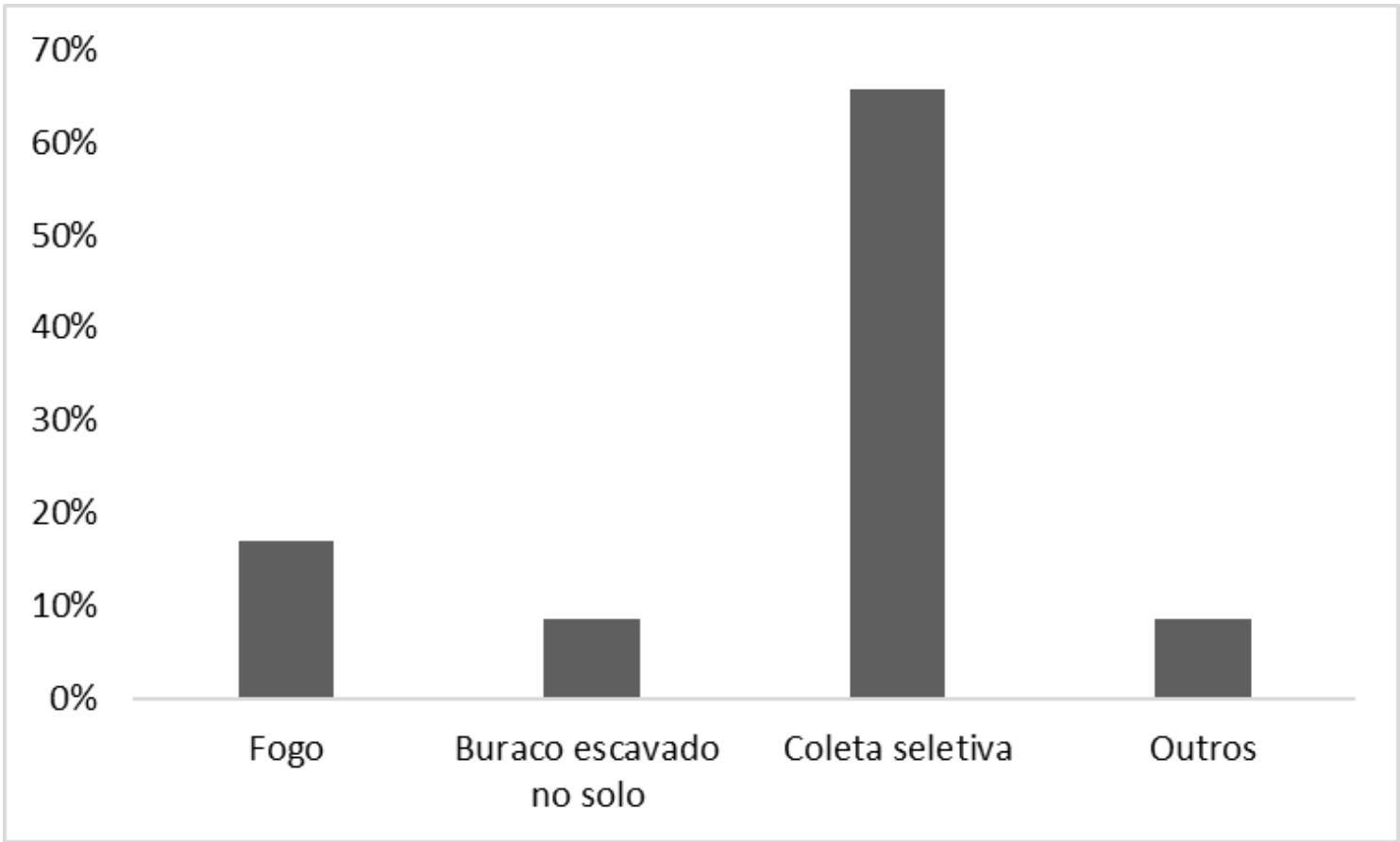

Figura 4: Local utilizado para descarte do resíduo seco (reciclável), região oeste de Santa Catarina. Fonte: Os autores, 2018.

Este dado deve-se ao fato que alguns entrevistados consideraram como "outros", ou justificaram por meio de observação, que depositam o lixo separado no armazém da propriedade por alguns dias e assim que há o acumulo de certa quantidade, transportam este material até o local de descarte na cidade ou o destinam para o lixão mais próximo às residências. Outros alegaram doar o lixo acumulado aos catadores de lixo reciclável em cooperativa especializada, e alternativas de descarte como pelo uso do fogo $(17,1 \%)$ e enterro em buraco escavado no solo $(8,6 \%)$ também foram constatados no presente trabalho. 
Resultado semelhante encontra-se no trabalho realizado por Pedroso (2010, p. 32), onde $54,5 \%$ dos entrevistados depositam o lixo de forma correta em lixeiras, no entanto o descarte ainda é realizado erroneamente, pois cerca de $30,3 \%$ é descartado por meio de fogo e $15,1 \%$ por meio de um buraco escavado no solo.

Em estudo realizado por Ceretta, Silva e Rocha (2013, p. 22), a queima dos resíduos sólidos é citada por $37 \%$ pelas famílias entrevistadas, sendo um dos principais métodos utilizados para sua destinação final.

A queima destes resíduos pode ocasionar sérios problemas ao ambiente e à saúde dos moradores que residem nessas localidades, pois possuem vários elementos químicos na sua composição, principalmente inorgânicos, que causam a contaminação aeróbica e riscos de incêndios (CERETTA; SILVA; ROCHA, 2013, p. 22).

O uso das queimadas ou soterramentos para a eliminação desses resíduos é uma prática inadequada devido aos impactos negativos ao ambiente. Ao enterrar o resíduo sem critérios de seleção, muitos moradores podem danificar bens fundamentais para a produção na agricultura, como o solo (CERETTA; SILVA; ROCHA, 2013, p. 19).

Àqueles que realizam descarte do lixo na própria propriedade, $71,4 \%$ disseram que o local de descarte não fica próxima à residência, o mesmo percentual alegou ainda que o local onde é depositado o resíduo doméstico é livre de animais silvestres, roedores, pássaros ou insetos (moscas, baratas, formigas), o que é um ponto positivo, pois segundo a Fundação Nacional de Saúde-FUNASA (2013), os principais vetores associados ao lixo e transmissores de doenças são insetos e ratos.

Questionou-se também a respeito do fornecimento de orientação em educação ambiental proveniente de órgãos públicos, como prefeitura, ONG's ou outra instituição, com objetivo de orientar sobre a destinação do lixo produzido em sua propriedade (Figura 5).

Constatou-se que $80 \%$ dos entrevistados nunca receberam visitas de órgãos públicos em suas propriedades com o objetivo de orientar, levantar situações ou tirar dúvidas a respeito do assunto, o que demonstra falta de atenção do poder público com esta problemática ambiental na zona rural. 


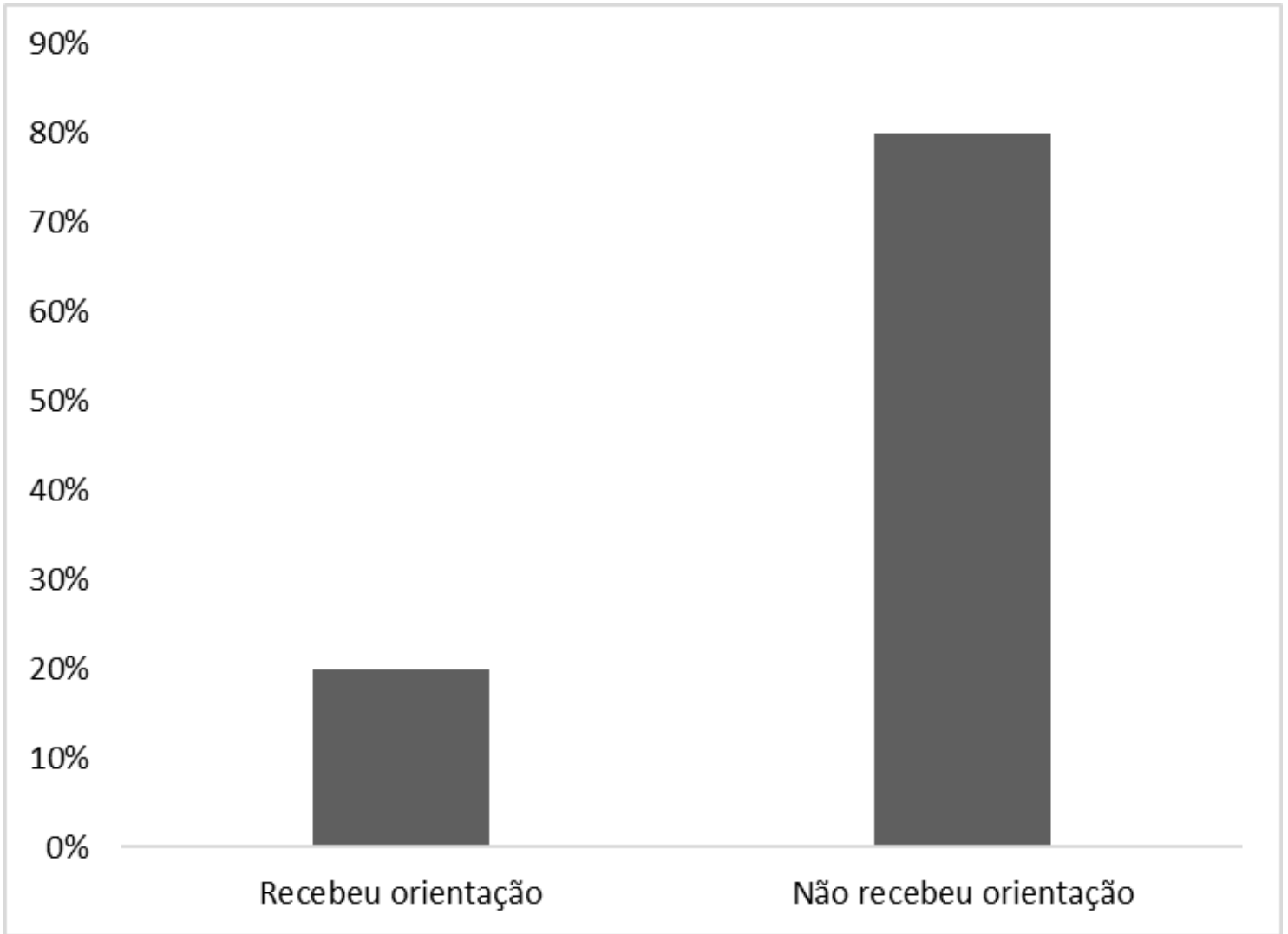

Figura 5: Recebimento de orientação sobre a correta destinação dos resíduos na região oeste de Santa Catarina. Fonte: Os autores, 2018.

Valores semelhantes podem ser observados em trabalho realizado por (MAZZA et al., 2014, p. 697), que questionou seus entrevistados se a propriedade já recebeu recomendações ou exigências por algum órgão (ou empresa) municipal ou estadual, para o controle de resíduos sólidos gerados na propriedade. De acordo com os dados obtidos pela entrevista, $57,6 \%$ das propriedades disseram nunca terem recebido recomendações ou exigências por algum órgão municipal ou estadual, para o controle de resíduos sólidos, e $32,20 \%$ salientam que já obtiveram, enquanto $10,20 \%$ obtiveram parcialmente.

Com relação aos programas de formação acerca do tema educação ambiental, $57,1 \%$ dos entrevistados disseram que nenhum dos membros da família participou de algum evento ou palestra relacionado ao assunto, ofertados pelas instituições acima mencionadas, o que confirma a carência de informações recebidas pela população da zona rural.

Em estudo realizado por Ceretta, Silva e Rocha (2013, p. 23), com relação à participação em eventos sobre educação ambiental, $53 \%$ responderam que já participaram de palestras e reuniões onde foram tratados assuntos referentes à poluição do meio ambiente provocada pelo lixo doméstico ou tóxico, como pilhas e baterias. 
Segundo Tolfo (2011, p. 435) educação ambiental é conhecida como um fator importante na contribuição do chamado "desenvolvimento sustentável", pois possibilita o processo de aprendizado e valorização dos recursos naturais e embora se reconheça a importância da conscientização, a educação ambiental ainda não é um mecanismo muito presente no país.

Quando questionados sobre o interesse em participar de eventos que abordam o assunto "lixo", apenas $42,8 \%$ dos entrevistados disseram que participariam de algum evento desta natureza se tivessem oportunidade, o que deixa claro que a questão ambiental não é apenas de responsabilidade de órgão governamentais ou ONG's, pois o interesse do público alvo é essencial para o sucesso de qualquer campanha. Resultado semelhante foi encontrado por Ceretta, Silva e Rocha (2013, p. 23 ), onde $46 \%$ das famílias pesquisadas responderam que não participariam desses eventos.

Isso demonstra que a participação da comunidade precisa ser estimulada, e isto parte da conscientização da problemática, a qual, muitas vezes não ocorre, devido, principalmente, a falta de acesso a meios de comunicação ou internet.

Destaca-se, ainda, a importância das escolas no processo de repasse de conhecimentos e informações para a comunidade, pois, uma vez que os estudantes recebem instruções adequadas, estes podem estar levando o conhecimento para dentro de suas casas e de suas famílias.

Visto as diversas formas de descarte de resíduos sólidos utilizadas pela população, questionou-se sobre o porquê da não utilização de uma forma ambientalmente correta de descarte, onde $66 \%$ dos entrevistados declarou não realizar a forma correta de descarte pelo fato de não possuir local adequado para isto, o que deve-se à distância da sua moradia aos locais destinados a coleta de lixo, como simples lixeiros comunitários como ocorre nas cidades, enquanto que outra parcela da população diz não receber nenhuma cobrança a respeito desta problemática, e, portanto, não tem preocupação em realizar o correto descarte (Figura 6). 


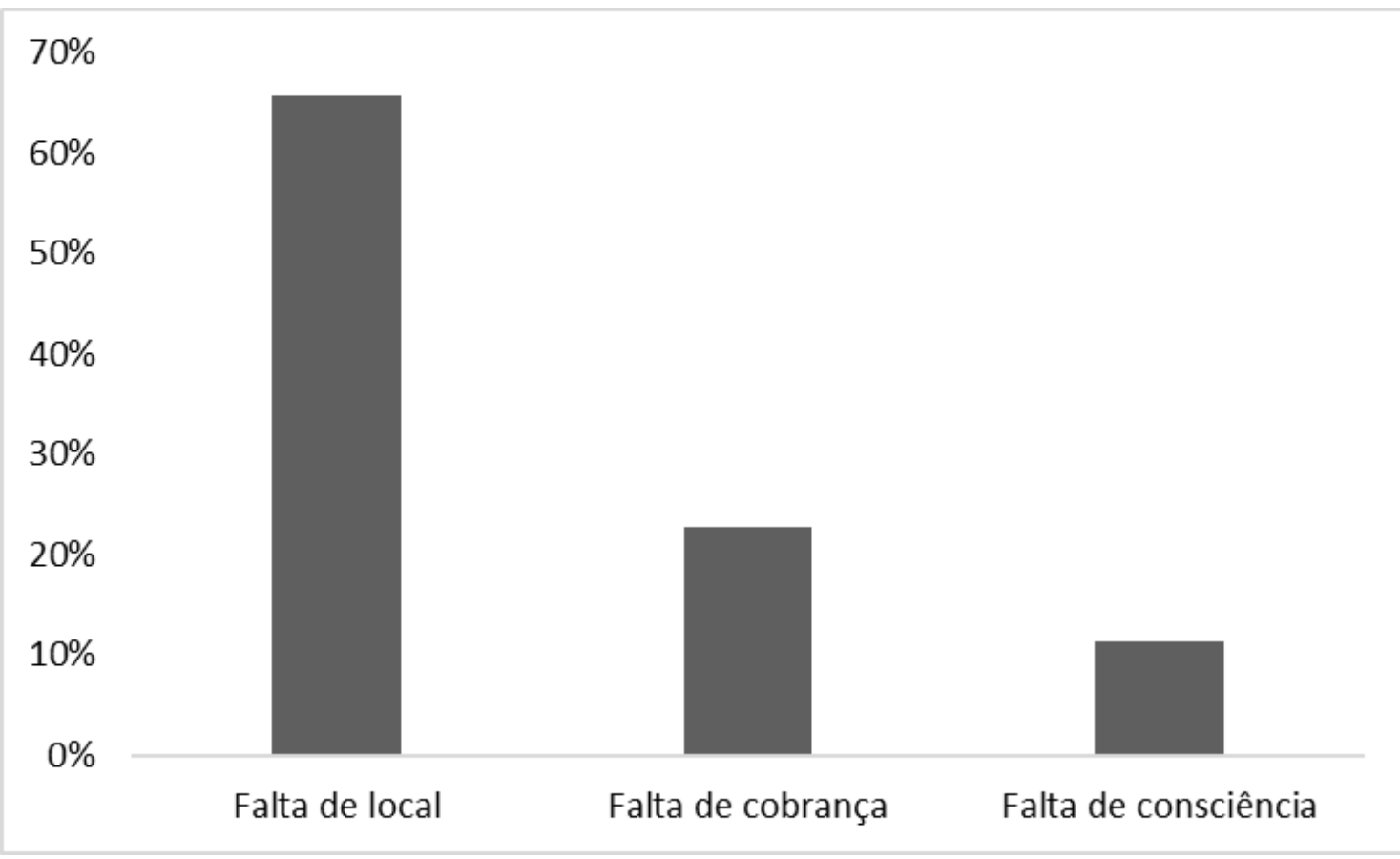

Figura 6: Dificuldades encontradas por moradores de área rural para a correta destinação dos resíduos sólidos na região oeste de Santa Catarina. Fonte: Os autores, 2018.

Resultado semelhante foi observado por Pedroso (2010, p. 33), onde $72,72 \%$ dos entrevistados reclamaram da falta de divulgação e orientação a respeito do tema, outros $51,51 \%$ dizem não serem incentivados a realizar o correto descarte dos seus resíduos, enquanto $24,24 \%$ alegam não se importarem a respeito do assunto.

\section{Conclusões}

Constatou-se que a separação dos resíduos sólidos é realizada na maioria das propriedades rurais, no entanto, a destinação aceitável é dada apenas à fração orgânica (hortas e composteiras), enquanto o restante dos resíduos continua sendo descartado de forma errônea ou onerosa devido a necessidade de transporte do resíduo para outras localidades.

A conscientização da população entrevistada a respeito da importância da correta gestão dos resíduos sólidos no meio rural e os reflexos causados na qualidade de vida das famílias ainda não se encontra plenamente formada e concretizada, sendo necessário maior atenção das autoridades responsáveis pelas questões ambientais, sociais e de saúde no processo de conscientização da população rural.

Diante dos fatos apresentados, fica evidente que a educação ambiental possui importante papel no sucesso de políticas públicas que venham a ser aplicadas nesta região. 


\section{Referências}

CERETTA, G. F; SILVA, F. K; ROCHA,A.C. Gestão e a problemática dos resíduos sólidos domésticos na área rural do município de São João-PR. Revista ADMpg Gestão Estratégica, Ponta Grossa, v. 6, n. 1, p. 17-25, 2013.

DURAZZINI, A.M.S; PARADELO, E.S. LIXO RURAL NO BRASIL: a problemática da destinação correta de embalagens vazias de agrotóxicos e a realização de coleta seletiva. Revista Agrogeoambiental, Pouso Alegre, v. 2, n. 2, p. 57-63, 2010.

FREIRE, E.A; ROLIM, F.S; LUSTOSA, F.P.G; SOUSA, F.J.D. A problemática da destinação dos resíduos sólidos no território rural: o caso do Sítio Boi Morto. Ciência e Sustentabilidade - CeS, Juazeiro do Norte, v. 2, n. 2, p. 51-62, 2016.

FRIESTINO, J.K.O; SILVA, O.M.P; NASCIMENTO, M.C.N. Condições Sanitárias no Oeste de Santa Catarina: Construindo um Diagnóstico das Populações Rurais e Pequenas Comunidades. Revista Brasileira de Ciências da Saúde, São Caetano do Sul, v. 19, n. 2, p. 109-116, 2015.

FUNASA- FUNDAÇÃO Nacional de Saúde. Resíduos sólidos e a saúde da comunidade: Informações Técnicas sobre a Interrelação Saúde, Meio Ambiente e Resíduos Sólidos. Brasília, 2013.

INSTITUTO BRASILEIRO DE GEOGRAFIA E ESTATÍSTICA. Censo Demográfico 2010: famílias e domicílios (resultados da amostra). Rio de Janeiro, 2012. Disponível em: <http://censo2010.ibge.gov.br/> Acesso em: 24 out., 2017.

MAZZA, V. M. DE S.; MADRUGA, L. R. DA R. G.; ÁVILA, L. V.; et al. Gestão De Resíduos Sólidos Em Propriedades Rurais De Municípios Do Interior Do Estado Do Rio Grande Do Sul. RAMA - Revista em Agronegócios e Meio Ambiente, v. 7, n. 3, p. 683-706, 2014.

MMA - Ministério do Meio Ambiente. Planos Municipais de Gestão Integrada de Resíduos Sólidos. 2015. Disponível em <http://www.mma.gov.br/cidadessustentaveis/residuos-solidos/instrumentos-da-politica-de-residuos/planosmunicipais-de-gest\%C3\%A3o-integrada-de-res\%C3\%ADduos-s\%C3\%B3lidos> Acesso em: 29 jun., 2018.

PASQUALI, Luiz. Composição gravimétrica de resíduos sólidos recicláveis domiciliares no meio rural de Chopinzinho/PR. 2012. 66 f. Dissertação (Mestrado em Desenvolvimento Regional) - Universidade Tecnológica Federal do Paraná, Pato Branco, 2012.

PLANO NACIONAL DE RESÍDUOS SÓLIDOS. 2011. Disponível em $<$ http://www.mma.gov.br/estruturas/253/ publicacao/253 publicaca0020220120 41757> Acesso em: 29 jun., 2018.

PEDROSO, H. F. E. Destinação e armazenagem de resíduos sólidos em propriedades rurais. 2010. (Trabalho de Conclusão de Curso/ Administração) - Universidade Federal do Rio Grande do Sul - UFGRS, Porto Alegre, 2010. 
PERSICH, J.C; SILVEIRA, D.D. Gerenciamento de resíduos sólidos - a importância da educação ambiental no processo de implantação da coleta seletiva de lixo - o caso de ljuí/RS. Revista Eletrônica em Gestão, Educação e Tecnologia Ambiental, v. 4, n. 4, p. 416-426, 2011.

PONTES,T; RODRIGUES,S.A; OLIVEIRA,P.A; CERVI,R.G; O descarte do lixo doméstico das propriedades rurais da região de Botucatu. IX Sintagro Simpósio Nacional de Tecnologia em Agronegócio, Botucatu-SP, 2017.

TOLFO, V.N.B; Educação ambiental na zona rural: uma análise a partir de uma escola no interior do município de Vitória das Missões/RS. Revista Eletrônica em Gestão, Educação e Tecnologia Ambiental, v.4, n. 4, p. 434-440, 2011.

WANGEN, D.R.B; FREITAS, I.C.B. Compostagem doméstica: alternativa de aproveitamento de resíduos sólidos orgânicos. Revista Brasileira de Agroecologia, v. 5, n. 2, p. 81-88, 2010. 
Apêndice 1: Questionário aplicados aos alunos do ensino médio e pós médio.

1) Número de pessoas que moram em sua residência:

Distância da sua propriedade da cidade:

2) Você sabe o que é coleta seletiva de lixo?

$\mathrm{Km}$.

( ) $\operatorname{Sim}($ ) Não

3) Qual a importância da coleta seletiva?
( ) Nenhuma importância ( ) Pouca importância
( ) Importante

( ) Muito importante ( ) Extremamente importante

4) Como você entende lixo, meio ambiente e qualidade de vida?

( ) Nenhuma relação ( ) Alguma relação ( ) Muita relação

5) Você participaria de alguma palestra ou curso de educação ambiental para melhoria da destinação do lixo dentro de sua propriedade?

( ) $\operatorname{Sim}$ ( ) Não

6) Você se preocupa com a preservação do meio ambiente?
( ) Sempre
( ) As vezes
( ) Raramente
( ) Nunca

7) Qual as dificuldades para a destinação correta do lixo na sua propriedade?

( ) Falta de local para colocar o lixo ( caminhão coletor) ( ) Falta de cobrança

( ) Falta de consciência

8) Na sua residência é feita a separação do lixo orgânico do reciclável?

( ) $\operatorname{Sim}($ ) Não

9) Se realizada a separação, onde você deposita o lixo orgânico? (restos de alimentos, cascas, legumes...).

( ) Horta ( ) Composteira ( ) Burraco escavado no solo

10) Onde você deposita/descarta o lixo seco? (Plástico, vidro, papel e outros)

( ) Fogo ( ) Burraco escavado no solo ( ) coleta seletiva/ caminhão

() outros Onde?

11) O local onde o lixo é descartado fica próximo a sua residência?

( ) Sim ( ) Não

12) O local onde é depositado o lixo doméstico reúne animais silvestres (ratos, pássaros e outros) e insetos (moscas, baratas, formigas e outros)?

( ) $\operatorname{Sim}($ ) Não

13) Sua propriedade já recebeu a visita de algum órgão público (Prefeitura, ONGs, outros) com o objetivo de orientar sobre a destinação do lixo doméstico produzido na sua propriedade?

( ) Sim ( ) Não

14) Alguém de sua família já participou de algum evento/ palestra sobre Educação Ambiental em que foram tratados de assuntos como a poluição do meio ambiente e doenças provocada pelo lixo doméstico?

( ) Sim ( ) Não

15) No seu município existe algum serviço público de coleta de lixo domiciliar na zona rural?

( ) Sim, é realizada a coleta ( ) Não existe coleta.

16) Existe algum sistema de coleta permanente ou periódico de lixo seco? (embalagem de agrotóxicos, lixo eletrônico...)

( )Não ( ) Sim Qual? 